\title{
Reduction of a Pancreatic Tumor after Total Removal of an ACTH Secreting Pituitary Tumor: Differential Diagnosis of Cushing's Syndrome
}

\author{
TETSUO HASHIBA, YoUICHI SAITOH, NOBUYUKI ASANUMA*, HARUHIKO KOUHARA*, \\ TOMOYUKI MARUO, TOSHIYUKI FUJINAKA, SOJI KASAYAMA* AND TOSHIKI YOSHIMINE \\ Department of Neurosurgery, Osaka University Graduate School of Medicine, 2-2 Yamadaoka, Suita, Osaka 565-0871, Japan \\ *Department of Molecular Medicine, Osaka University Graduate School of Medicine, 2-2 Yamadaoka, Suita, Osaka 565-0871, Japan
}

\begin{abstract}
Endocrinologic tests sometimes fail to distinguish adrenocorticotropic hormone (ACTH)-secreting pituitary adenoma from ectopic ACTH-secreting tumor. The authors experienced a case of Cushing's disease associated with a pancreatic tumor. Venous sampling contributed to the final diagnosis of Cushing's disease in this complex case, while endocrinologic tests showed paradoxical results. A 54-year-old woman presented with Cushing's syndrome and pancreatic tumor. Magnetic resonance imaging (MRI) failed to reveal a pituitary tumor, but a gadolinium-enhanced tumor with cystic components was seen in the pancreatic tail. Results of conventional endocrinologic tests suggested ectopic ACTH syndrome, but venous sampling including cavernous sinus sampling indicated an ACTH-secreting pituitary adenoma. Transsphenoidal surgery revealed a pituitary microadenoma, and total removal of the tumor was achieved. Postoperative abdominal MRI revealed that the pancreatic tumor diminished gradually without treatment. Selective cavernous sinus sampling was useful for distinguishing ACTH-secreting pituitary adenoma from ectopic ACTH syndrome in this complex case. This was a rare case in which the pancreatic tumor diminished after total removal of the ACTHsecreting pituitary adenoma.
\end{abstract}

Key words: Cushing's disease, Ectopic ACTH syndrome, Pancreatic neoplasm, Petrosal sinus sampling

(Endocrine Journal 53: 203-208, 2006)

CUSHING'S disease accounts for approximately twothirds of the cases of Cushing's syndrome [1]. Most patients of ACTH dependent Cushing's syndrome have adrenocorticotropic hormone (ACTH)-secreting pituitary microadenoma, but ectopic ACTH syndrome, which causes $9-18 \%$ of Cushing's syndrome [2], is sometimes responsible. Laboratory studies fail to accurately distinguish these two etiologies in $10-30 \%$ of cases [3-6], and the sensitivity of magnetic resonance imaging (MRI) for detection of ACTH-secreting pituitary microadenoma is reported to range from $54 \%$ to 91\% [7-10]. Therefore, ectopic ACTH syndrome is

Received: August 10, 2005

Accepted: January 13, 2006

Correspondence to: Youichi SAITOH, M.D., Ph.D., Department of Neurosurgery, Osaka University Graduate School of Medicine, 2-2 Yamadaoka, Suita, Osaka 565-0871, Japan sometimes misdiagnosed.

Herein, we describe a patient with ACTH-secreting pituitary adenoma and a mass in the pancreatic tail that was detected by abdominal MRI. Laboratory studies suggested ectopic ACTH syndrome, but selective cavernous sinus sampling (CSS) indicated the presence of ACTH-secreting pituitary adenoma. The pituitary adenoma was surgically removed and subsequently the pancreatic tumor decreased in size without any treatment. We discuss the difficult differential diagnosis in this case and describe the rare phenomenon that occurred after surgery. 


\section{Case Report}

\section{Clinical findings and laboratory studies}

A 54-year-old woman presented with central obesity, moon face, and muscle weakness. Cushing's syndrome was suspected, and she was admitted to Osaka University Hospital. Relevant laboratory values included sodium $148 \mathrm{mmol} / \mathrm{l}$, potassium $2.9 \mathrm{mmol} / \mathrm{l}$, fasting blood glucose $210 \mathrm{mg} / \mathrm{dl}, \mathrm{HbA} 1 \mathrm{c} 7.9 \%$, and urinary 17 hydroxycorticosteroid $45.8 \mathrm{mg} /$ day. Overnight low$(1 \mathrm{mg})$ and high-dose $(8 \mathrm{mg})$ dexamethasone suppression tests showed lack of suppression of serum ACTH and cortisol levels, and there was no ACTH or cortisol response to intravenous injection of corticotropinreleasing hormone $(\mathrm{CRH})(100 \mu \mathrm{g})$. The serum $\mathrm{CRH}$ level was $9.1 \mathrm{pg} / \mathrm{ml}$ (normal range: $3.2-14.7 \mathrm{pg} / \mathrm{ml}$; Radio Immuno Assay method, SRL, Tokyo, Japan). After intravenous administration of $10 \mu \mathrm{g}$ of desmopressin, the cortisol and ACTH levels did not increase significantly. The summary of clinical data including endocrinologic tests is shown in Table 1. On the basis of these laboratory findings, ectopic ACTH syndrome was suggested.

Table 1. Summary of preoperative clinical data including endocrine tests

\begin{tabular}{lcc}
\hline Basic value & & \\
ACTH $(\mathrm{pg} / \mathrm{ml})$ & 121 & \\
Cortisol $(\mu \mathrm{g} / \mathrm{dl})$ & 47.7 & \\
Urinary free cortisol $(\mathrm{ng} / \mathrm{dl})$ & 1603 & \\
17-OHCS $(\mathrm{mg} /$ day) & 45.8 & \\
17-KS $(\mathrm{mg} / \mathrm{day})$ & 18 & \\
ACTH daily rhythm & $7: 00$ & $23: 00$ \\
ACTH $(\mathrm{pg} / \mathrm{ml})$ & 165 & 78 \\
Cortisol $(\mu \mathrm{g} / \mathrm{dl})$ & 47.7 & 33.1 \\
CRH loading test & pre & post \\
ACTH $(\mathrm{pg} / \mathrm{ml})$ & 193 & 154 \\
Cortisol $(\mu \mathrm{g} / \mathrm{dl})$ & 46.6 & 43.5 \\
1mg Dexamethasone loading test & pre & post \\
ACTH $(\mathrm{pg} / \mathrm{ml})$ & 165 & - \\
Cortisol $(\mu \mathrm{g} / \mathrm{dl})$ & 55.4 & 63 \\
8mg Dexamethasone loading test & pre & post \\
ACTH $(\mathrm{pg} / \mathrm{ml})$ & 270 & - \\
Cortisol $(\mu \mathrm{g} / \mathrm{dl})$ & 113.9 & 135.9 \\
dDAVP loading test & pre & post \\
ACTH $(\mathrm{pg} / \mathrm{ml})$ & 273 & 315 \\
Cortisol $(\mu \mathrm{g} / \mathrm{dl})$ & - & 121.7 \\
\hline 17-OHCS, 17-hydroxycorticosteroid; & $17-\mathrm{KS}, \quad 17-\mathrm{ketosteroid;}$ \\
dDAVP, desmopressin; pre, preload value; post, peak value after \\
loading.
\end{tabular}

\section{Imaging studies}

MRI of the pituitary region, including dynamic study, failed to reveal microadenoma (Fig. 1A). Abdominal MRI revealed a $3 \mathrm{~cm} \times 3 \mathrm{~cm}$ mass lesion of low intensity in the tail of the pancreas that was partly enhanced by gadolinium (Fig. 2A). Abdominal positron emission tomography with 2-[fluorine-18] fluoro-2deoxy-D-glucose (FDG-PET) showed an uptake area consistent with the location of the lesion (Fig. 3A). Endoscopic retrograde cholangiopancreatography revealed a solid and partly cystic mass lesion in the pancreatic tail with communication between the lesion and the main pancreatic duct. Accordingly, the pancreatic tumor was considered the most likely source of the $\mathrm{ACTH}$.

\section{Bilateral CSS of ACTH}

Venous sampling was performed to determine the origin of the excessive serum ACTH. The catheter was

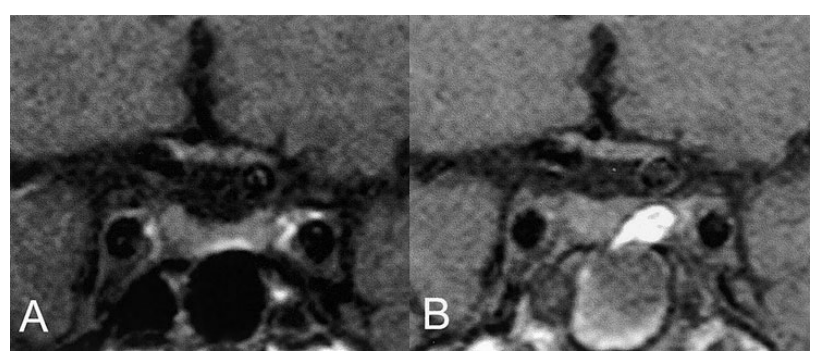

Fig. 1. (A) Preoperative head MRI. No apparent microadenoma was shown in the sella. (B) Postoperative head MRI. Fat tissue was replaced at the resected cavity.

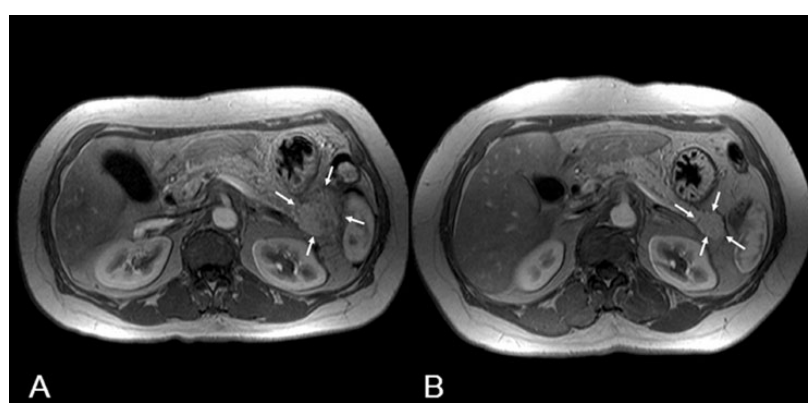

Fig. 2. Abdominal MRI with contrast enhancement (A) Preoperative. A solid mass with cystic components was shown with contrast enhancement in the pancreatic tail. (B) Postoperative (7 months after operation). The mass diminished after the total removal of the ACTH secreting pituitary adenoma. 
introduced from the right femoral vein and the blood samples were taken at several sites. The left inferior petrosal sinus (IPS) was hypoplastic, and a microcatheter was introduced into the cavernous sinuses from the right IPS. The levels of ACTH at the respective sites and the levels of prolactin (PRL), which was measured at both cavernous sinuses as reference to ensure adequate venous sampling, are shown in Table 2 . The levels of ACTH in the inferior vena cava (peripheral to the junction with the bilateral renal veins), right cavernous sinus, and left cavernous sinus were 51, 242, and 302 $\mathrm{pg} / \mathrm{ml}$, respectively. The central-to-peripheral ratio of the serum ACTH level was 4.74 in the right cavernous sinus and 5.92 in the left. The left-to-right gradient was 1.24 and a normalized ACTH/PRL the left-to-right gradient was 1.34 .

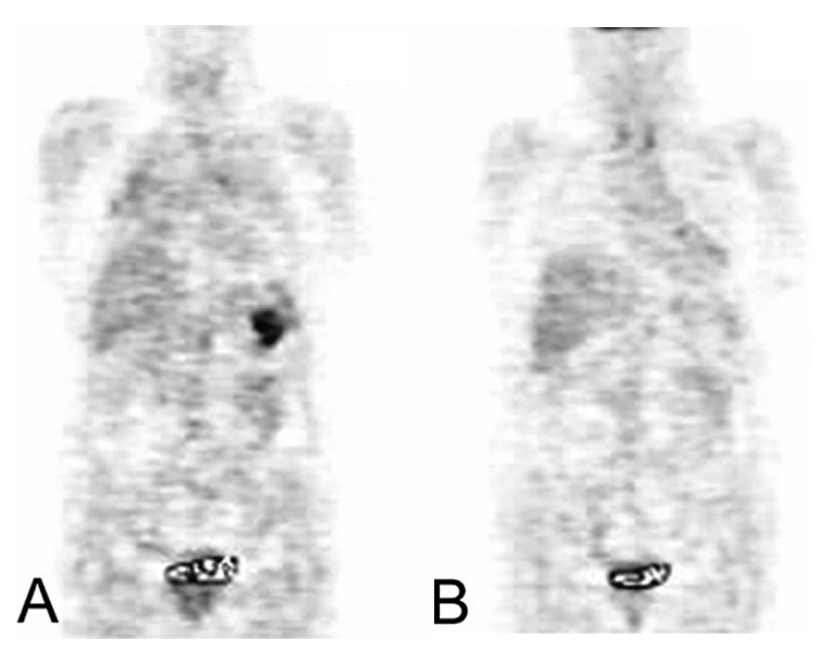

Fig. 3. (A) Preoperative FDG-PET. There is an uptake of FDG consistent with the tumor in the pancreatic tail. (B) Postoperative FDG-PET (4 months after operation). No uptake was shown in the same region.

Table 2. Summary of selective venous sampling

\begin{tabular}{lccc}
\hline & $\begin{array}{c}\text { ACTH } \\
(\mathrm{pg} / \mathrm{ml})\end{array}$ & $\begin{array}{c}\text { Cortisol } \\
(\mu \mathrm{g} / \mathrm{dl})\end{array}$ & $\begin{array}{c}\text { PRL } \\
(\mathrm{ng} / \mathrm{ml})\end{array}$ \\
\hline $\begin{array}{l}\text { IVC } \\
\quad \text { (peripheral of bilateral renal vein) }\end{array}$ & 51 & 14.2 & \\
$\begin{array}{l}\text { lt. renal vein } \\
\quad \text { peripheral of lt. adrenal vein) }\end{array}$ & 42 & 10.6 & \\
$\begin{array}{l}\text { lt. renal vein } \\
\quad \text { (central of lt. adrenal vein) }\end{array}$ & 41 & 10.8 & \\
$\begin{array}{l}\text { lt. adrenal vein } \\
\text { hepatic vein } \\
\text { rt. cavernous sinus }\end{array}$ & 42 & 25.8 & \\
lt. cavernous sinus & 51 & 11.9 & \\
\hline
\end{tabular}

IVC, inferior vena cava; rt, right; lt, left.

\section{Neurosurgical intervention}

Although the laboratory and abdominal MRI and FDG-PET findings suggested an ectopic ACTH-secreting tumor located in the pancreas, an ACTH-secreting pituitary adenoma was strongly suspected on the basis of the venous sampling. Therefore, the patient underwent transsphenoidal surgery. Upon opening of the dura of the sella on the left side, a grayish tumor was found. The tumor size seemed to be about 2 or $3 \mathrm{~mm}$ in diameter, which was compressed. The tumor and surrounding normal tissue were removed and the cavity was replaced by the abdominal fat. The postoperative MRI is shown in Fig. 1B. Histologic examination revealed a pituitary adenoma that was stained positively with ACTH antibody.

\section{Postoperative course}

Two weeks after surgery, daily cortisol secretion had normalized $(15.1 \mu \mathrm{g} / \mathrm{dl}$ early in the morning and 4.9 $\mu \mathrm{g} / \mathrm{dl}$ at midnight), and a dexamethasone $(1 \mathrm{mg})$ suppression test decreased ACTH (from $26 \mathrm{pg} / \mathrm{ml}$ to $8 \mathrm{pg}$ / $\mathrm{ml}$ ) and cortisol (from 15.1 to $2.8 \mu \mathrm{g} / \mathrm{dl}$ ) secretion. Moreover, the insulin loading test resulted in responsive increase of ACTH and cortisol (Table 3). But the response was poor, and it was considered to be compatible with postoperative status of cured Cushing's disease. Therefore, appropriate hydrocortisone replacement was administered to the patient for a while after surgery. The summary of the postoperative clinical data including endocrinologic tests is shown in Table 3.

Table 3. Summary of postoperative clinical data including endocrinologic tests

\begin{tabular}{lcc}
\hline Basic value & & \\
ACTH $(\mathrm{pg} / \mathrm{ml})$ & 19 & \\
Cortisol $(\mu \mathrm{g} / \mathrm{dl})$ & 18.2 & \\
Urinary free cortisol $(\mathrm{ng} / \mathrm{dl})$ & 90 & \\
17-OHCS $(\mathrm{mg} /$ day $)$ & 10.6 & \\
17-KS $(\mathrm{mg} / \mathrm{day})$ & 2.8 & \\
ACTH daily rhythm & $7: 00$ & $23: 00$ \\
ACTH $(\mathrm{pg} / \mathrm{ml})$ & 26 & $<5.0$ \\
Cortisol $(\mu \mathrm{g} / \mathrm{dl})$ & 15.1 & 4.9 \\
1mg Dexamethasone loading test & pre & post \\
ACTH $(\mathrm{pg} / \mathrm{ml})$ & 26 & 8 \\
Cortisol $(\mu \mathrm{g} / \mathrm{dl})$ & 15.1 & 2.8 \\
Insulin loading test & pre & post \\
ACTH $(\mathrm{pg} / \mathrm{ml})$ & 9.7 & 14.8 \\
Cortisol $(\mu \mathrm{g} / \mathrm{dl})$ & 25 & 37 \\
\hline
\end{tabular}


Interestingly, the pancreatic tumor decreased gradually in size (Fig. 2B), and FDG-PET showed diminished uptake at 4 months after surgery (Fig. 3B).

About two years after surgery, she has been free from any clinical symptom and the pancreatic tumor has never grown again on the subsequent radiological studies.

\section{Discussion}

In this case, it was difficult to distinguish ACTHsecreting pituitary adenoma from ectopic ACTHsecreting pancreatic tumor. The results of CSS provided the final diagnosis. After total removal of the ACTH-secreting adenoma the serum ACTH level normalized, and the patient was cured.

ACTH-secreting pituitary microadenoma cannot always be identified in imaging studies such as computed tomography [7, 11] and MRI [7-10] studies. Moreover, pituitary adenoma is detected incidentally by MRI in $10 \%$ of healthy persons; false positivity can also occur [12]. Non-invasive endocrine laboratory studies, including low- and high-dose dexamethasone suppression tests $[4,5]$, metyrapone stimulation [3], and peripheral CRH challenge tests [6], are often used to distinguish pituitary adenoma from ectopic sources of excessive ACTH. However, each of these tests fails to distinguish the two etiologies in $10-30 \%$ of cases [3-6]. Therefore, differential diagnosis of ACTHdependent Cushing's syndrome remains, on occasion, a considerable clinical challenge.

Our patient, who presented with symptoms consistent with Cushing's syndrome, had a solid and partly cystic tumor in the pancreas and showed lack of suppression of serum ACTH and cortisol levels in the high-dose dexamethasone test and lack of ACTH and cortisol response to the CRH test. Therefore, ectopic ACTH syndrome was suspected. However, ectopic ACTH-secreting pancreatic tumor causing Cushing's syndrome is relatively rare, accounting for about $10 \%$ of all cases of ectopic ACTH syndrome and about 2\% of all pancreatic endocrine tumors [13,14]. Moreover, most ACTH-producing islet cell tumors are malignant, and the majority of cases involve liver metastasis by the time of diagnosis [15].

Association of pancreatic tumor with pituitary microadenoma is sometimes seen in cases of multiple endocrine neoplasia type 1 (MEN 1) $[16,17]$. Yoshimoto et al. reviewed 106 cases of MEN 1 and reported that Cushing's disease was present in about $5 \%$ of patients [17]. Miyagawa et al. reported a case of MEN 1 consisting of Cushing's disease, primary hyperparathyroidism, and insulin-glucagonoma; the patient was treated successfully by transsphenoidal pituitary adenomectomy, subtotal parathyroidectomy, and enucleation of the pancreatic tumors [16].

Because we suspected an association of two different tumors in our case, we performed selective CSS even though endocrine laboratory studies suggested that an ectopic ACTH-secreting tumor in the pancreas was the likely cause of the excessive serum ACTH. CSS findings indicated the presence of an $\mathrm{ACTH}$-secreting tumor, and thus CSS was very useful for distinguishing $\mathrm{ACTH}$-secreting pituitary adenoma from ectopic ACTH syndrome in our case.

A number of studies have evaluated the role of venous sampling by microcatheter in the diagnosis of ACTH-dependent Cushing's syndrome [18-22]. Oldfield et al. reported that a central-to-peripheral ACTH ratio of greater than 2.0 has a sensitivity of $95 \%$ and specificity of $100 \%$ and after CRH administration the ratio of greater than 3.0 has a sensitivity and a specificity of $100 \%$ in inferior petrosal sinus sampling (IPSS) [18]. However, additional experience has revealed some false-negative results. Using the same cut-off value, a false-negative rate of $1-10 \%$ in patients with proven Cushing's disease has been reported [23-26]. False-negative results with IPSS have been attributed to wide variation of venous drainage [24]. Recently, Findling et al. suggested that the measurement of PRL (as an index of fidelity of pituitary venous effluent during IPSS) and the establishment of a normalized ACTH/PRL petrosal sinus to peripheral ratio will identify patients with Cushing's disease who fail to have a peak ACTH inferior petrosal sinus to peripheral ratio greater than 3.0 after CRH [27].

On the other hand, Teramoto et al. described the usefulness of CSS compared to IPSS and suggested that the tentative cutoff ratio is 5 for the diagnosis of pituitary lesions [19]. In our case, we obtained a ratio of greater than 5 in left cavernous sinus and fortunately the origin of excessive ACTH was in the pituitary gland. However, Teramoto et al. also reported that basal $\mathrm{C} / \mathrm{P}$ ratios in the cavernous sinus exceeded 10 in most cases of Cushing's disease [19]. Taking these facts into consideration, for a more reliable diagnosis we should perform CSS after CRH administration or 
measure the level of PRL from peripheral vein and cavernous sinus, and calculate a normalized ACTH/PRL petrosal sinus to peripheral ratio.

As for lateralization of the tumor in the pituitary gland, Oldfield et al. also reported that a greater than 1.4-fold difference in ACTH concentrations between the two inferior petrosal sinuses accurately localized the microadenoma in $68 \%$ of cases during basal sampling [18]. The accuracy of determining lateralization by means of bilateral inferior petrosal sinus sampling is reported to be approximately $75 \%$ [28], and that by means of bilateral CSS ranges widely from $40 \%$ to $94 \%[19,29,30]$. In this case, the basal left-to-right gradient showed 1.24, but the normalized ACTH/PRL left-to-right gradient showed 1.34, which was near 1.4. Therefore, we opened the dura surrounding the sella on the left side. The pituitary adenoma was located on the left side of the pituitary gland and was totally removed. Therefore, it can be said that selective CSS is necessary for differential diagnosis of ACTH-dependent Cushing's syndrome, especially in cases of difficult differential diagnosis. Flitsch et al. also recommend CSS for diagnostic purposes in complex cases [31]. However, Suzuki et al. reported a rare case with an ACTHproducing ectopic pituitary adenoma in the sphenoid sinus [32]. Therefore, we should consider the possibility of such a case even if CSS indicated the pituitary origin as the more likely source of excessive ACTH.

It was interesting that the pancreatic tumor decreased in size. Unfortunately, histologic confirmation has not been obtained, but we speculate that the pancreatic tumor was hormone dependent because it diminished postoperatively with changes in the hormonal environment such as decreases in the serum ACTH and cortisol levels. In the literature, there was no report that a pancreatic tumor diminished after total removal of an ACTH producing pituitary adenoma. Ours is the first report of such a rare and interesting case.

\section{References}

1. Newell-Price J, Trainer P, Besser M, Grossman A (1998) The diagnosis and differential diagnosis of Cushing's syndrome and pseudo-Cushing's states. Endocr Rev 19: 647-672.

2. Wajchenberg BL, Mendonca BB, Liberman B, Pereira MA, Carneiro PC, Wakamatsu A, Kirschner MA (1994) Ectopic adrenocorticotropic hormone syndrome. Endocr Rev 15: 752-787.

3. Avgerinos PC, Yanovski JA, Oldfield EH, Nieman LK, Cutler GB Jr (1994) The metyrapone and dexamethasone suppression tests for the differential diagnosis of the adrenocorticotropin-dependent Cushing syndrome: a comparison. Ann Intern Med 121: 318-327.

4. Dichek HL, Nieman LK, Oldfield EH, Pass HI, Malley JD, Cutler GB Jr (1994) A comparison of the standard high dose dexamethasone suppression test and the overnight 8-mg dexamethasone suppression test for the differential diagnosis of adrenocorticotropin-dependent Cushing's syndrome. J Clin Endocrinol Metab 78: 418-422.

5. Flack MR, Oldfield EH, Cutler GB Jr, Zweig MH, Malley JD, Chrousos GP, Loriaux DL, Nieman LK (1992) Urine free cortisol in the high-dose dexamethasone suppression test for the differential diagnosis of the Cushing syndrome. Ann Intern Med 116: 211-217.

6. Nieman LK, Oldfield EH, Wesley R, Chrousos GP, Loriaux DL, Cutler GB Jr (1993) A simplified morning ovine corticotropin-releasing hormone stimulation test for the differential diagnosis of adrenocorticotropin- dependent Cushing's syndrome. J Clin Endocrinol Metab 77: 1308-1312.

7. Buchfelder M, Nistor R, Fahlbusch R, Huk WJ (1993) The accuracy of CT and MR evaluation of the sella turcica for detection of adrenocorticotropic hormonesecreting adenomas in Cushing disease. AJNR Am J Neuroradiol 14: 1183-1190.

8. Colombo N, Loli P, Vignati F, Scialfa G (1994) MR of corticotropin-secreting pituitary microadenomas. AJNR Am J Neuroradiol 15: 1591-1595.

9. Newton DR, Dillon WP, Norman D, Newton TH, Wilson CB (1989) Gd-DTPA-enhanced MR imaging of pituitary adenomas. AJNR Am J Neuroradiol 10: 949-954.

10. Peck WW, Dillon WP, Norman D, Newton TH, Wilson CB (1989) High-resolution MR imaging of pituitary microadenomas at $1.5 \mathrm{~T}$ : experience with Cushing disease. AJR Am J Roentgenol 152: 145-151.

11. Saris SC, Patronas NJ, Doppman JL, Loriaux DL, Cutler GB Jr, Nieman LK, Chrousos GP, Oldfield EH (1987) Cushing syndrome: pituitary CT scanning. Radiology 162: 775-777.

12. Hall WA, Luciano MG, Doppman JL, Patronas NJ, Oldfield EH (1994) Pituitary magnetic resonance imaging in normal human volunteers: occult adenomas in the general population. Ann Intern Med 120: 817-820.

13. Kent RB 3rd, van Heerden JA, Weiland LH (1981) Nonfunctioning islet cell tumors. Ann Surg 193: 185190. 
14. Odell W (1985) Humoral manifestations of cancer. In: Wilson JD, Foster DW (eds) Textbook of Endocrinology, edn 7. Saunders, Philadelphia: 1327-1331.

15. Doppman JL, Nieman LK, Cutler GB Jr, Chrousos GP, Fraker DL, Norton JA, Jensen RT (1994) Adrenocorticotropic hormone-secreting islet cell tumors: are they always malignant? Radiology 190: 59-64.

16. Miyagawa K, Ishibashi M, Kasuga M, Kanazawa Y, Yamaji T, Takaku F (1988) Multiple endocrine neoplasia type I with Cushing's disease, primary hyperparathyroidism, and insulin-glucagonoma. Cancer 61: 1232-1236.

17. Yoshimoto K, Saito S (1991) Clinical characteristics in multiple endocrine neoplasia type 1 in Japan: a review of 106 patients. Nippon Naibunpi Gakkai Zasshi 67: 764-774 (In Japanese).

18. Oldfield EH, Doppman JL, Nieman LK, Chrousos GP, Miller DL, Katz DA, Cutler GB Jr, Loriaux DL (1991) Petrosal sinus sampling with and without corticotropinreleasing hormone for the differential diagnosis of Cushing's syndrome. N Engl J Med 325: 897-905.

19. Teramoto A, Yoshida Y, Sanno N, Nemoto S (1998) Cavernous sinus sampling in patients with adrenocorticotrophic hormone-dependent Cushing's syndrome with emphasis on inter- and intracavernous adrenocorticotrophic hormone gradients. J Neurosurg 89: 762768.

20. Findling JW, Raff H (1999) Newer diagnostic techniques and problems in Cushing's disease. Endocrinol Metab Clin North Am 28: 191-210.

21. Raff H, Findling JW (2003) A physiologic approach to diagnosis of the Cushing syndrome. Ann Intern Med 138: 980-991.

22. Kaltsas GA, Giannulis MG, Newell-Price JD, Dacie JE, Thakkar C, Afshar F, Monson JP, Grossman AB, Besser GM, Trainer PJ (1999) A critical analysis of the value of simultaneous inferior petrosal sinus sampling in Cushing's disease and the occult ectopic adrenocorticotropin syndrome. J Clin Endocrinol Metab 84: 487-492.

23. Bonelli FS, Huston J 3rd, Carpenter PC, Erickson D, Young WF Jr, Meyer FB (2000) Adrenocorticotropic hormone-dependent Cushing's syndrome: sensitivity and specificity of inferior petrosal sinus sampling. AJNR Am J Neuroradiol 21: 690-696.

24. Doppman JL, Chang R, Oldfield EH, Chrousos G, Stratakis CA, Nieman LK (1999) The hypoplastic infe- rior petrosal sinus: a potential source of false-negative results in petrosal sampling for Cushing's disease. $J$ Clin Endocrinol Metab 84: 533-540.

25. Lopez J, Barcelo B, Lucas T, Salame F, Alameda C, Boronat M, Salto L, Estrada J (1996) Petrosal sinus sampling for diagnosis of Cushing's disease: evidence of false negative results. Clin Endocrinol (Oxf) 45: 147-156.

26. Swearingen B, Katznelson L, Miller K, Grinspoon S, Waltman A, Dorer DJ, Klibanski A, Biller BM (2004) Diagnostic errors after inferior petrosal sinus sampling. J Clin Endocrinol Metab 89: 3752-3763.

27. Findling JW, Kehoe ME, Raff H (2004) Identification of patients with Cushing's disease with negative pituitary adrenocorticotropin gradients during inferior petrosal sinus sampling: prolactin as an index of pituitary venous effluent. J Clin Endocrinol Metab 89: 60056009.

28. Lefournier V, Martinie M, Vasdev A, Bessou P, Passagia JG, Labat-Moleur F, Sturm N, Bosson JL, Bachelot I, Chabre O (2003) Accuracy of bilateral inferior petrosal or cavernous sinuses sampling in predicting the lateralization of Cushing's disease pituitary microadenoma: influence of catheter position and anatomy of venous drainage. J Clin Endocrinol Metab 88: 196-203.

29. Doppman JL, Nieman LK, Chang R, Yanovski J, Cutler GB Jr, Chrousos GP, Oldfield EH (1995) Selective venous sampling from the cavernous sinuses is not a more reliable technique than sampling from the inferior petrosal sinuses in Cushing's syndrome. J Clin Endocrinol Metab 80: 2485-2489.

30. Oliverio PJ, Monsein LH, Wand GS, Debrun GM (1996) Bilateral simultaneous cavernous sinus sampling using corticotropin-releasing hormone in the evaluation of Cushing disease. AJNR Am J Neuroradiol 17: 1669-1674.

31. Flitsch J, Ludecke DK, Knappe UJ, Grzyska U (2002) Cavernous sinus sampling in selected cases of Cushing's disease. Exp Clin Endocrinol Diabetes 110: 329 335.

32. Suzuki J, Otsuka F, Ogura T, Kishida M, Takeda M, Tamiya T, Nishioka T, Tanaka Y, Hashimoto K, Makino H (2004) An aberrant ACTH-producing ectopic pituitary adenoma in the sphenoid sinus. Endocr J 51: $97-$ 103. 